\title{
Epidemiology of suicide and attempted suicide derived from the health system database in the Islamic Republic of Iran: 2001-2007
}

\author{
M.B. Saberi-Zafaghandi, ${ }^{1}$ A. Hajebi, ${ }^{1}$ S. Eskandarieh ${ }^{2}$ and M. Ahmadzad-Asl ${ }^{1}$
}

$$
\begin{aligned}
& \text { وبائيات الانتحار وححاولات الانتحار المستمدة من قاعدة معطيات النظام الصحي في جمهورية إيران الإسلامية: 2001-2007 }
\end{aligned}
$$

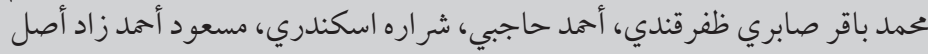

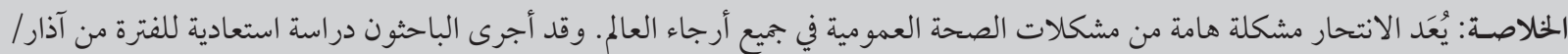

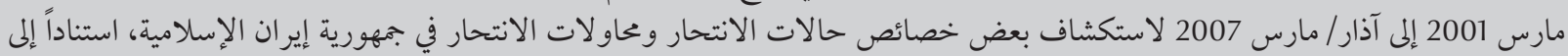

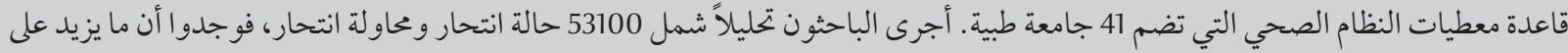

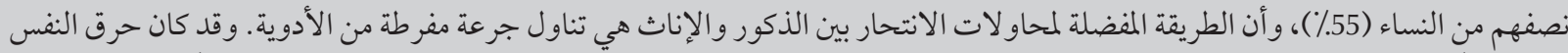

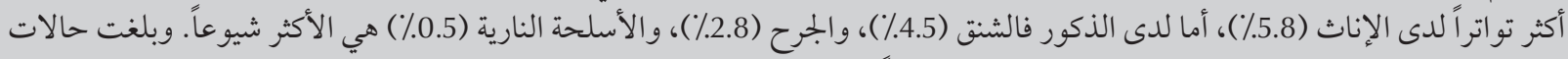

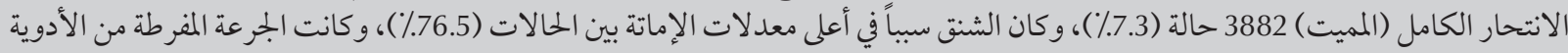

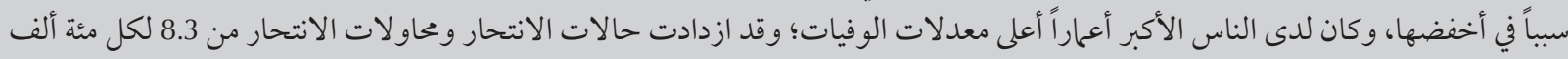

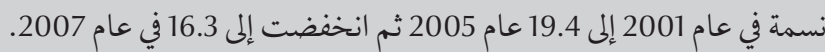

ABSTRACT Suicide is an important public health problem worldwide. A retrospective study from March 2001 to March 2007 examined some characteristics of cases of suicide and attempted suicide in the Islamic Republic of Iran based on the health system database of 41 medical universities. A total of 53100 cases of suicide and attempted suicide were analysed. Just over half were among women (55.0\%). The most usual method of attempted suicide among both males and females was drug overdose. Self-burning was more frequent in females (5.8\%) while hanging $(4.5 \%)$, cutting $(2.8 \%)$ and firearms $(0.5 \%)$ were more common in males. There were 3883 (7.3\%) completed (fatal) suicides. Hanging had the highest case fatality rate (76.5\%) and drug overdose the lowest (2.3\%). Older people had a higher mortality rate. Suicide and attempted suicides increased from 8.3 per 100000 population in 2001 to 19.4 in 2005, then declined to 16.3 in 2007.

Épidémiologie du suicide et des tentatives de suicide à partir de la base de données du système de santé en République islamique d'Iran entre 2001 et 2007

RÉSUMÉ Le suicide représente un problème de santé publique important dans le monde. Une étude rétrospective menée entre mars 2001 et mars 2007 a examiné certaines caractéristiques des cas de suicide et de tentatives de suicide en République islamique d'Iran à partir de la base de données du système de santé de 41 facultés de médecine. Au total, 53100 cas de suicides et de tentatives de suicide ont été analysés. À peine plus de la moitié concernait des femmes (55,0\%). La méthode la plus fréquemment utilisée des tentatives de suicide chez les hommes comme chez les femmes était une surdose médicamenteuse. L'immolation par le feu était plus fréquente chez les femmes (5,8\%) alors que les recours à la pendaison (4,5\%), au sectionnement $(2,8 \%)$ et aux armes à feu $(0,5 \%)$ étaient plus nombreux chez les hommes. Dans l'étude, 3883 tentatives de suicide ont été mortelles (7,3\%). La pendaison était associée au taux le plus élevé de décès (76,5\%) et la surdose médicamenteuse, au taux le plus faible (2,3\%). Les personnes plus âgées avaient un taux de mortalité plus élevé. Les cas de suicide et de tentative de suicide ont augmenté, passant de 8,3 pour 100000 en 2001 à 19,4 en 2005, puis sont retombés à 16,3 en 2007. 


\section{Introduction}

Estimates suggest that there are more than 20 to 50 million suicide attempts worldwide, leading to 1 million deaths by suicide annually (greater than the mortality rate due to war and homicide combined) [1]. Based on a World Health Organization (WHO) report, suicide is the 13th cause of death in the world and the 3rd cause of death in the age group 15-34 years [2]. In the 1990s, evidence of rising suicide rates persuaded $\mathrm{WHO}$ to introduce a target of decreasing the suicide rate in countries as one of its goals in public health programmes [3].

In the Islamic Republic of Iran statistics from the forensic medical organization in 2001 showed suicide rates of 5.7 and 3.1 per 100000 people respectively in men and women [4]. A national study of the burden of diseases in 2004 revealed that the disability-adjusted life years (DALY) for suicide and self-harm behaviours were 206.2 per 100000 population [5]. A study in 1999 demonstrated that $75 \%$ of suicide attempts were due to drugs and $20 \%$ and $4 \%$ to poisoning and cutting respectively [6]. Studies in other countries have shown variations in methods of suicide by demographic characteristics such as sex and age $[7,8]$. In the Islamic Republic of Iran the most common reported suicide method in men was found to be hanging and in women was self-burning [9]. The Islamic Republic of Iran and Georgia have the highest suicide rate in women among western Asian countries [4].

In the current study we used the data from the suicide registration system in all the medical universities in Islamic Republic of Iran to describe some of the characteristics of cases of suicide and attempted suicide from March 2001 to March 2007. Knowledge of these characteristics is needed to design better targeted suicide prevention interventions.

\section{Methods}

This was a retrospective, descriptive, cross-sectional study of all cases of suicide (attempted and completed) reported from March 2001 to March 2007 in the Islamic Republic of Iran.

\section{Data collection}

We collected all data from 41 universities of medical sciences and health services using a uniform questionnaire which was designed by the Mental Health Office at the Ministry of Health in Tehran. For each case the data collected were: outcome (fatal/nonfatal), demographic data (sex, age and marital status) and method used. These variables were selected on the basis of previous, similar studies [10,11].

In each medical university we selected a member of the mental health staff to run the project. They were trained in a national workshop for 6 hours on the study objectives, procedure and the questionnaire. During the process of data gathering, they had direct contact with the Mental Health Office to help them rectify any problems. They were responsible for training other staff in district health centres, which are subsets of and are supervised by the medical universities.

Each district health centre has a mental health section which routinely collects data on suicide events from the rural and urban health centres, general and mental hospitals and the death registration system. At university level, the person in charge checked the questionnaires and did the primary organization of the data. Finally, data were sent to the Mental Health Office, and at the Ministry of Health we organized the data again and double-checked the data entry.

\section{Statistical analysis}

Data was analysed using the software package SPSS, version 16. Descriptive indices were calculated and reported. To analyse the relationship between variables, we used the chi-squared test. We also did logistic regression analysis to estimate the odds ratio (OR) for each variable in order to predict factors leading to completed suicide. $P$ values < 0.05 were considered significant.

\section{Results}

A total of 53100 reported cases of suicide (attempted and completed) were entered in the study. More than half of the cases (55.0\%) were among females. The range of ages was 11-93 years and the mean age was 25.2 years old; $77.1 \%$ of cases were among were those aged $\leq 30$ years and only $4.7 \%$ among those $\geq 51$ years old (Table 1 ). More cases were among single than married people, although data about marital status was missing for nearly half of cases $(45.8 \%)$ (Table 1). Drug overdose (73.0\%) was the most commonly used method in attempted and completed suicides, followed by poisoning (10.6\%); firearms $(0.2 \%)$ were the least used method (Table 1).

Table 2 shows the methods of suicide (attempted and completed) by age, sex and marital status. Self Self-burning was a more frequent method used in women than men (5.4\% versus $2.5 \%$ respectively) $\left(\chi^{2}=326.1, P<0.001\right)$, whereas hanging and cutting were used by more men than women ( $4.2 \%$ versus $0.8 \%$ and $2.6 \%$ versus $0.5 \%$ respectively) $\left(\chi^{2}=662.8, P<0.001\right.$ and $\chi^{2}=404.6, P<$ 0.001 ; respectively). Drug overdose was slightly more frequent among women than men (74.9\% versus $69.3 \%)\left(\chi^{2}\right.$ $=6.85, P=0.009)$. Age-specific analysis of methods showed that the rate of hanging rose steadily with increased age group (from $1.8 \%$ for those aged $\leq 21$ years to $5.4 \%$ for those aged $\geq 51$ years) $\left(\chi^{2}=231.4, P<0.001\right)$ (Table 2). The rate of self-burning increased until the age 50 years and then declined slightly. The rate of drug overdose decreased with age from $76.5 \%$ at age $\leq 21$ years to $51.6 \%$ at $\geq 51$ years $\left(\chi^{2}=909.6, P<\right.$ 


\begin{tabular}{|c|c|c|c|c|c|c|c|c|c|}
\hline \multirow[t]{2}{*}{ Variable } & \multicolumn{2}{|c|}{ All cases } & \multicolumn{2}{|c|}{$\begin{array}{l}\text { Attempted } \\
\text { (nonfatal) } \\
(n=49217)\end{array}$} & \multicolumn{2}{|c|}{$\begin{array}{c}\text { Completed } \\
(\text { fatal }) \\
(n=3883)\end{array}$} & \multirow[t]{2}{*}{$\begin{array}{l}\text { Case } \\
\text { fatality } \\
\text { rate }^{\mathrm{a}}\end{array}$} & \multirow{2}{*}{$\begin{array}{l}\text { Completed suicide } \\
\qquad \text { OR }(95 \% \mathrm{Cl})\end{array}$} & \multirow[t]{2}{*}{$P$-value } \\
\hline & No. & $\%$ & No. & $\%$ & No. & $\%$ & & & \\
\hline Total & 53100 & 100.0 & 49217 & 100.0 & 3883 & 100.0 & 7.3 & & \\
\hline \multicolumn{10}{|l|}{ Sex } \\
\hline Female & 29225 & 55.0 & 27312 & 55.5 & 1913 & 49.3 & 6.5 & $0.79(0.74-084)$ & $<0.001$ \\
\hline Male & 23652 & 44.5 & 21759 & 44.2 & 1893 & 48.8 & 8.0 & Reference & \\
\hline Missing data & 223 & 0.4 & 146 & 0.3 & 77 & 2.0 & - & & \\
\hline \multicolumn{10}{|l|}{ Age (years) } \\
\hline$\leq 20$ & 19832 & 37.3 & 18659 & 37.9 & 1173 & 30.2 & 5.9 & $0.43(0.37-0.49)$ & $<0.001$ \\
\hline $21-30$ & 21148 & 39.8 & 19753 & 40.1 & 1395 & 35.9 & 6.6 & $0.45(0.39-0.51)$ & $<0.001$ \\
\hline $31-40$ & 5415 & 10.2 & 4909 & 10.0 & 506 & 13.0 & 9.3 & $0.63(0.55-0.74)$ & $<0.001$ \\
\hline $41-50$ & 2740 & 5.2 & 2425 & 4.9 & 315 & 8.1 & 11.5 & $0.81(0.68-0.96)$ & $<0.001$ \\
\hline$\geq 51$ & 2477 & 4.7 & 2145 & 4.4 & 332 & 8.6 & 13.4 & Reference & \\
\hline Missing data & 1488 & 2.8 & 1326 & 2.7 & 162 & 4.2 & - & - & \\
\hline \multicolumn{10}{|l|}{ Marital status } \\
\hline Single & 16499 & 31.1 & 15216 & 30.9 & 1283 & 33.1 & 7.8 & $0.39(0.22-0.68)$ & $<0.001$ \\
\hline Married & 12165 & 22.9 & 10793 & 21.9 & 1372 & 35.4 & 11.3 & $0.16(0.09-0.28)$ & $<0.001$ \\
\hline Divorced & 71 & 0.1 & 54 & 0.1 & 17 & 0.4 & 23.9 & Reference & \\
\hline Missing data & 24365 & 45.9 & 23154 & 47.1 & 1211 & 31.1 & - & - & \\
\hline \multicolumn{10}{|l|}{ Suicide method } \\
\hline Drug overdose & 38784 & 73.0 & 37880 & 77.0 & 904 & 23.3 & 2.3 & $0.01(0.01-0.01)$ & $<0.001$ \\
\hline Cutting & 763 & 1.4 & 734 & 1.5 & 29 & 0.7 & 3.8 & $0.01(0.01-0.04)$ & $<0.05$ \\
\hline Poisoning & 5626 & 10.6 & 5531 & 10.9 & 275 & 7.1 & 4.9 & $0.02(0.01-0.03)$ & $<0.001$ \\
\hline Narcotic overdose & 359 & 0.7 & 319 & 0.6 & 40 & 1.0 & 11.1 & $0.06(0.04-0.10)$ & $<0.001$ \\
\hline Self-burning & 2164 & 4.1 & 713 & 1.4 & 1451 & 37.4 & 67.1 & $0.73(0.49-1.08)$ & $<0.05$ \\
\hline Hanging & 1239 & 2.3 & 291 & 0.6 & 948 & 24.4 & 76.5 & $1.16(0.77-1.75)$ & $<0.05$ \\
\hline Firearm & 130 & 0.2 & 34 & 0.1 & 96 & 2.5 & 73.8 & Reference & \\
\hline Other methods & 441 & 0.8 & 375 & 0.8 & 66 & 1.7 & 14.9 & - & \\
\hline Missing data & 3594 & 6.8 & 3520 & 7.2 & 74 & 1.9 & - & - & \\
\hline
\end{tabular}

${ }^{a}$ Case fatality rate $=[$ fatal $/$ fatal + nonfatal $\left.)\right] \times 100$.

$O R=$ odds ratio; $C I=$ confidence interval.

0.001). Analysis of methods based on marital status showed that drug overdose was more prevalent among the single $(61.2 \%)$ than the divorced (57.7\%) $\left(\chi^{2}=733.9, P<0.001\right)$ (Table 2). Selfburning was more common among the divorced (18.3\%) than among married people $(9.3 \%)$ and singles $(4.5 \%)\left(\chi^{2}=\right.$ 1715.3, $P<0.001)$.

There were 3883 completed suicides, a fatality rate of $7.3 \%$. The fatality rate among females (6.5\%) was significantly lower than males (8.0\%) (OR $=0.79,95 \%$ CI: 0.74-084). (Table 1). The 3 most commonly used methods among the fatal cases were self-burning (37.4\%), hanging (24.4\%) and drug overdose (23.3\%) (Table 1). When the case fatality rates were calculated for the different methods of suicide, hanging $(76.5 \%)$, firearms (73.8\%) and self-burning $(67.1 \%)$ were significantly more likely to lead to death than the other methods $(P<0.001)$ (Table 1$)$. Drug overdose had the lowest case fatality rate (2.3\%). Logistic regression analysis confirmed that suicide method was significantly correlated with suicide mortality. Age of subjects also had an independent effect on mortality rate, with the mortality rate increasing each year by about $2 \%$.

The trend of suicides (attempted and completed) showed an increase from 8.3 per 100000 population in 2001, the first year of suicide registration, to 19.4 in 2005, after which it declined to 16.3 by the end of the data collection in March 2007 (Figure 1).

\section{Discussion}

In this study, attempted suicide was more prevalent among young people, 


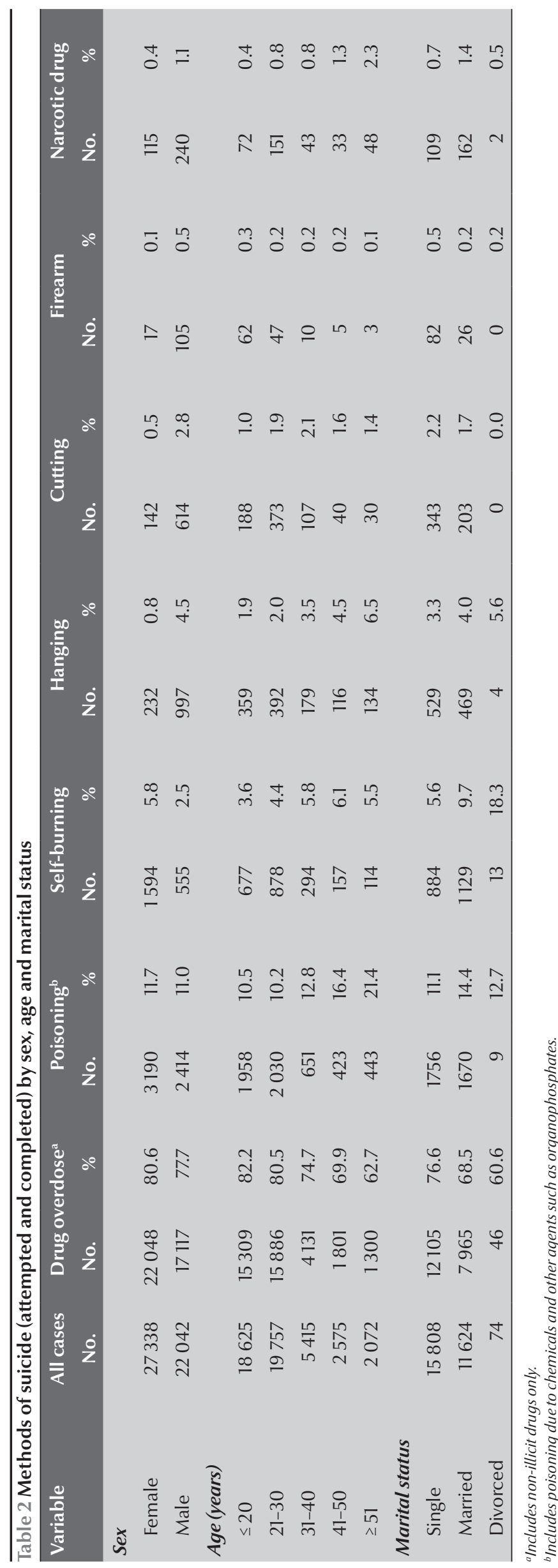

females and those of single marital status. On the other hand completed suicides showed a different demographic profile, with the fatality rate being higher among males, older people and those who were divorced. A study in Egypt found that the majority of completed suicide victims were young males [12]. Other studies in the Islamic Republic of Iran have reported that the rate of attempted suicide among females was higher than males and among younger people and single marital status [13]. Al-Ansari and Ali in Bahrain reported that young females were at high risk for suicide attempt and low risk for fatal suicide [14]. Khan and Reza showed that $75 \%$ of nonfatal suicides in Pakistan were among those aged under 30 years and compared to men women were younger and more often married [15]. Mechri et al. in Tunisia found that repeated suicide attempts were more common in divorced or separated people [16].

Our findings showed the most common method of suicide (attempted and completed) was drug overdose ( $73.0 \%$ of all cases used this method). The method with the highest case fatality rate, however, was hanging ( $76.6 \%$ of cases using this method died). Drug overdose had the lowest fatality rate (2.3\%), a figure which is comparable with other studies [17]. A study in 8 states in the United States, found that poisoning were the most common method among those attempting suicide and firearms by those dying by suicide [7].

Our study also revealed differences in methods of attempted and completed suicide based on some of the demographic factors. For instance, hanging and firearms were more prevalent among males and self-burning was more common among females. A 4-year retrospective survey in India demonstrated that males were more likely prefer to use hanging and poisoning whereas females more likely to prefer drowning and self-immolation [18]. Age-specific analysis of methods showed that the rate of hanging and self-burning rose with increased age. Coronfel in the Untied Arab Emirates showed that the age of the victims had no effect on the choice of the method used to commit suicide [19]. Analysis of methods by marital status showed that drug overdose was more prevalent among the single and self-burning was more common among the divorced

Studies show that when a person decides to attempt suicide, access to specific methods might be the factor that leads to translation of suicidal thoughts into action. In this situation the most easily available 


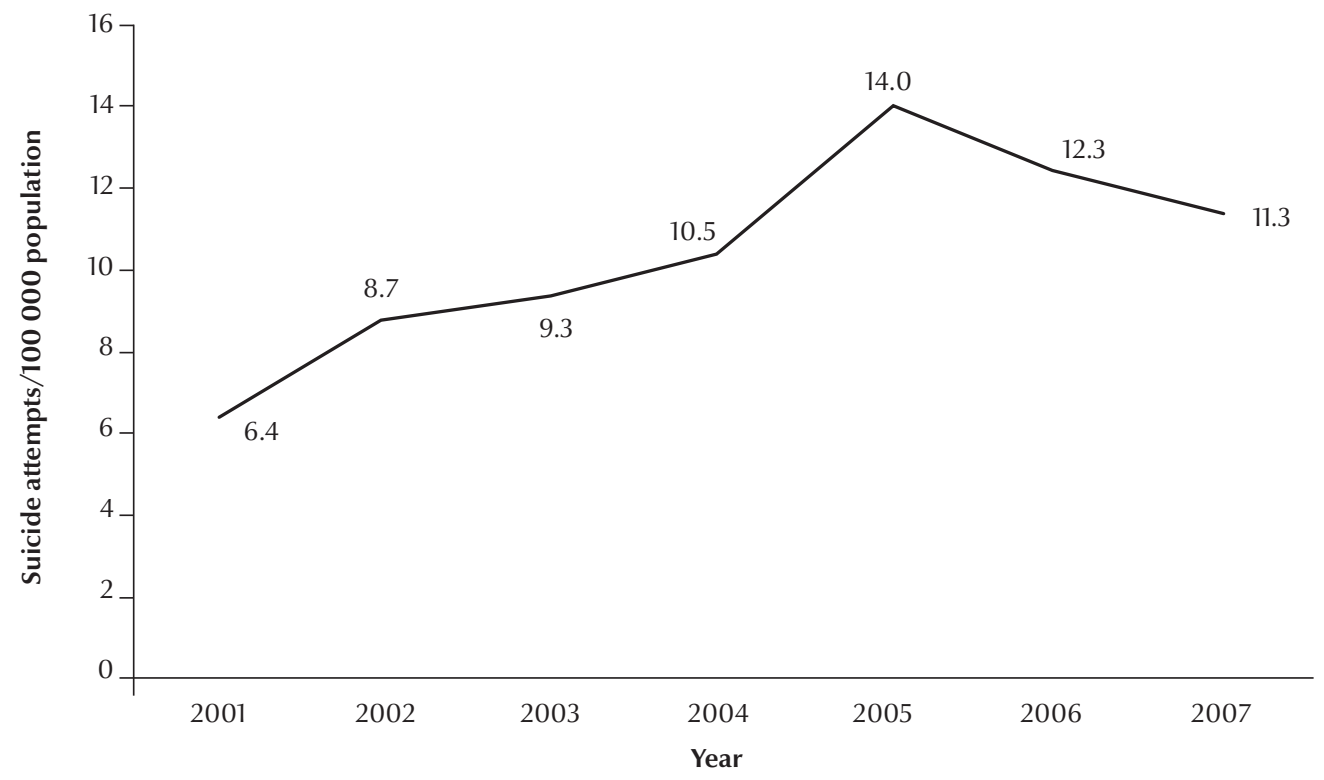

Figure 1 Trend of suicide (attempted and completed) in the Islamic Republic of Iran from 2001 to 2007

and most prevalent methods determine the outcome [20]. For example, in our country self-burning was more common in females [11] whereas firearms and hanging were more commonly used by men [9], presumably because access to guns is easier for males than females. On the other hand, hanging had a higher case fatality rate in this study. A 4-year retrospective study in the west coastal region of India concluded that the factors determining preferences of suicidal method between men and women are complex. This study reported that availability, accessibility, popularity and socioacceptability seem to be the major determinants in the choice of methods among males and females [10]. Vladeta et al. reported the international suicide patterns from the WHO mortality database. They believed that when a suicide method was popular in men it will often also be popular in women and vice versa. Therefore, underlying suicide patterns are tend to be country-specific, based on availability and acceptability of suicide methods not gender differences [21].

Some epidemiological studies reported characteristics of suicide behaviours in Islamic Republic of Iran. They revealed that young married women were at greatest risk of suicide behaviours by burns. They reported social, cultural, and economic factors may contribute to suicidal behaviour $[22,23]$.

Our study showed that $7.3 \%$ of all our cases were fatal. Similar studies in Islamic Republic of Iran have reported fatality rates between $5.0 \%$ and $11.1 \%$ $[9,24]$. These figures might be an indication of a rising suicide fatality rate in our country. Also the results revealed significant differences in the fatality rate of suicide methods. When we assessed predicting factors which increased the risk of fatality rate, the results showed that increasing age, regardless of sex and suicide method, increases the likelihood of completed suicide.

Our study showed an increased trend in the rate of suicide and attempted suicide between 2001 and 2005. This might be explained by the implementation of a suicide prevention programme in Islamic Republic of Iran. The programme was started in areas with a high suicide prevalence rate and then extended to other areas in the country by 2005 . This programme had two phases. In the first phase we trained general practitioners for detection, management and follow-up of patients with major depressive disorder, while in the second phase we tried to reinforce the suicide behaviour registration system around the country. We believe that the improved registration system from 2001 may have contributed to a higher rate of registering of suicides until 2005, when the suicide prevention programme began to gain effect such that the suicide rate decrease from 2005 to 2007 . Other studies in the country have reported that diagnosis and treatment of depression and also increased rate of antidepressant drug use have had a positive correlation with reduced suicide rates $[10,23]$. Reports from other countries show no uniform trend in suicide rates over the last two decades; some of them have claimed that the suicide rate has been decreased during recent decades while several reports found increasing suicide rates $[1,25,26]$.

Our study suffers from some limitations. First it is possible that the quality of data gathering across the medical 
universities was not homogenous because different rates of missing data were found. We found that the most important reason were lack of uniform methods and lack of intensive monitoring of data registration during previous years. While our sample is unlikely to include all of the cases of suicide behaviour in the country during the study period, it is probably representative of them. This is a common limitation in retrospective studies which are based on medical registration.

\section{Conclusions}

These were differences in the demographic characteristics of cases of attempted and completed suicide. Young, single women were more prone to suicide attempts while elderly, divorced males were more prone to completed suicide. Our study showed some differences in methods of suicide according to demographic factors, which may reflect differences in availability, accessibility and popularity of methods.

\section{Acknowledgements}

We wish to acknowledge mental health experts of medical universities and Mental Health Office, whose kind cooperation made this research possible. The authors would like to thank Professor Kamran Bagheri-Lankarani for his helpful comments and suggestions.

\section{References}

1. Kessler RC et al. Trends in suicide ideation, plans, gestures, and attempts in the United States, 1990-1992 to 2001-2003. Journal of the American Medical Association, 2005, 293:2487-2495.

2. Suicide prevention (SUPRE). World Health Organization [website] (http://www.who.int/mental_health/prevention/suicide/suicideprevent/en/, accessed 27 May 2012).

3. Platt $\mathrm{S}$ et al. Parasuicide in Europe: the WHO/EURO multicentre study on parasuicide. I. Introduction and preliminary analysis for 1989. Acta Psychiatrica Scandinavica, 1992, 85:97-104.

4. Moradi S, Khademi A. [Evaluation of suicides resulting in death in Iran, comparing with the world rates]. Legal Medicine, 2002. 8(27):21 [in Farsi].

5. [National burden of disease and injury of I.R. Iran in 2003]. Tehran, Ministry of Health and Medical Education, 2007 [in Farsi].

6. Zohor A, Aflatonian MR. Epidemiological study of attempted suicide in Jiroft, Kerman (autumn 2001). Fundamentals of Mental Health, 2002, 4:38.

7. Spicer RS, Miller TR. Suicide acts in 8 states: incidence and case fatality rates by demographics and method. American Journal of Public Health, 2000, 90:1885-1891.

8. Pesticides are a leading suicide method. Press release, 9 September 2006. World Health Organization (http://www.who. int/mediacentre/news/notes/2006/np24/en/, accessed 27 May 2012).

9. Mehran N. The comparison of psychosocial characteristics of suicide attempters with general population [Masters thesis]. Tehran, Tehran Psychiatry Institute, 2003.

10. Kanchan T, Menon A, Menezes RG. Methods of choice in completed suicides: gender differences and review of literature. Journal of Forensic Sciences, 2009, 54:938-942.

11. Alaghehbandan $\mathrm{R}$ et al. The role of marital status, literacy, and urbanity in suicidal behavior by burns in the province of Khorasan, Iran. Community Mental Health Journal, 2010, 47:181-185.

12. Gad ElHak SA et al. Fatal suicide cases in Port Said city, Egypt. Journal of Forensic and Legal Medicine, 2009, 16:266-268.

13. Nojomi $\mathrm{M}$ et al. Epidemiology of suicide attempters resorting to emergency departments in Karaj, Iran, 2003. European Journal of Emergency Medicine, 2008, 15:221-223.
14. Al Ansari A, Ali MK. Psychiatric and socioenvironmental characteristics of Bahraini suicide cases. Eastern Mediterranean Health Journal, 2009, 15:1235-1241.

15. Khan MM, Reza H. Gender differences in nonfatal suicidal behavior in Pakistan: significance of sociocultural factors. Suicide \& Life-Threatening Behavior, 1998, 28:62-68.

16. Mechri A et al. Les récidives suicidaires: etude comparative des caractéristiques des suicidants a répétition et des primosuicidants i admis aux urgences d'un hôpital général Tunisien [Repeat suicide attempts: characteristics of repeaters versus first-time attempters admitted in the emergency of a Tunisian general hospital]. L'Encéphale, 2005, 31:65-71.

17. Islambulchilar M, Islambulchilar Z, Kargar-Maher $\mathrm{MH}$. Acute adult poisoning cases admitted to a university hospital in Tabriz, Iran. Human and Experimental Toxicology, 2009, 28:185190.

18. Mohanty MK et al. An analysis of poisoning deaths in Manipal, India. Veterinary and Human Toxicology, 2004, 46(4):208-209.

19. Koronfel AA. Suicide in Dubai, United Arab Emirates. Journal of Clinical Forensic Medicine, 2002, 9:5-11.

20. Denning DG et al. Method choice, intent, and gender in completed suicide. Suicide \& Life-Threatening Behavior, 2000, 30:282-288.

21. Ajdacic-Gross $V$ et al. Methods of suicide: international suicide patterns derived from the WHO mortality database. Bulletin of the World Health Organization, 2008, 86:726-732.

22. Lari AR et al. Suicidal behavior by burns in the province of Fars, Iran. Crisis, 2009, 30:98-101

23. Groohi B et al. Suicidal behavior by burns among adolescents in Kurdistan, Iran: a social tragedy. Crisis, 2006, 27:16-21.

24. Yasami MT et al. [Epidemiological study of attempted suicide in Kerman, Iran]. Andisheh-va-raftar, 1998, 3, 15-35 [in Farsi].

25. Isacsson $\mathrm{G}$ et al. Decrease in suicide among the individuals treated with antidepressants: a controlled study of antidepressants in suicide, Sweden 1995-2005. Acta Psychiatrica Scandinavica, 2009, 120:37-44.

26. Largey M, Kelly CB, Stevenson M. A study of suicide rates in Northern Ireland 1984-2002. Ulster Medical Journal, 2009, 78:16-20. 